\title{
Endoscopic Collagen Spray - A Novel Method Which can be Used as an Adjunct to Conventional Hemostatic Techniques in Peptic Ulcer Bleeding
}

\author{
VG Mohan Prasad*, Madhura Prasad, Shujaath M Asif, KVKSN Murthy, Mithra Prasad, Gokul Kruba \\ Shanker, Anand Bharathan, Vadamalainathan G and Praveen M Patil
}

VGM Gastro Centre, Trichy road, Coimbatore, Tamil Nadu, India

${ }^{*}$ Corresponding author: Prasad VGM, VGM Gastro Centre 2100, Trichy road, Coimbatore, Tamil Nadu India, Tel: +91-422-2572202; E-mail: drvgm@rediffmail.com

Received date: June 21, 2017; Accepted date: January 18, 2018; Published date: January 22, 2018

Citation: Prasad VGM, Prasad M, Asif SM, Murthy KVKSN, Prasad M, et al. Endoscopic Collagen Spray- A Novel Method Which can be Used as an Adjunct to Conventional Hemostatic Techniques in Peptic Ulcer Bleeding. J Clin Gastroenterol Hepatol Vol.2: No.1: 1.

\section{Abstract}

Aim: To study endoscopic collagen spray as a hemostatic agent in peptic ulcer bleeding not controlled by conventional therapy.

Methods: In this prospective study, endoscopic collagen spray, VGM's Haemoseal spray has been used in the treatment of peptic ulcer bleeding, as a single agent or in combination with other agents. Haemoseal Spray Kit consists of air pump, Haemoseal probe, a $7.5 \mathrm{Fr}$ spray catheter, $230 \mathrm{~cm}$ in length and a pre-loaded collagen cartridge that contains 5 grams of powder. A maximum of 2 grams is applied depending on the area to be covered.

Results: Eighteen consecutive patients, who presented with peptic ulcer bleeding were included. There were sixteen patients with duodenal ulcer and two patients with gastric ulcer. The hemorrhagic ulcers were Forrest classification category $\mathrm{Ib}$ in sixteen patients and la in two patients. After spraying collagen, the bleeding stopped within seconds in all the patients. Repeat endoscopy after 48 hours showed no rebleeding. One patient had an arterial spurt from duodenal ulcer. Collagen spray was used initially as there was poor visibility. After 24 hours, repeat endoscopy revealed visible vessel with no bleeding. Hemoclipping could be achieved. There were no side effects experienced by the patients.

Conclusion: Collagen spray is a safe and effective endoscopic hemostatic agent in treatment of peptic ulcer bleeding not controlled by conventional therapy.

Keywords: Peptic ulcer bleeding; Endotherapy; Hemoclipping; Collagen spray; Epinephrine injection

\section{Introduction}

Peptic ulcers are the most common cause of acute nonvariceal upper gastrointestinal bleeding, accounting for around $40 \%$ of the cases. Endoscopic therapy reduces the rate of recurrence, need for surgery and transfusion of blood products [1]. Combination of endoscopic techniques is recommended in management. Hemoclipping and thermal coagulation are useful for spurters and non-bleeding visible vessel. Peptic ulcer with ooze has very few approved therapies. The current recommendation is peri-ulcer epinephrine ( 1 in 10,000) injection. It is a well-established fact that epinephrine should only be used as a combination therapy [2]. Hemostatic sprays provide an excellent option which can be used in combination with epinephrine for an oozing ulcer [3]. In this article we present a prospective study, where collagen has been used as an endoscopic hemostatic agent for peptic ulcer bleeding.

Hydrolyzed collagen is available as a viscous, amber aqueous solution or most commonly as off-white to white hygroscopic powder. It absorbs up to thirty times its own weight of water. It is commercially prepared by alkaline, enzymatic or acid hydrolysis from bovine or porcine sources. VGM's Haemoseal spray, (Shaili endoscopy), which is the agent used in this series, consists of powdered form of collagen derived from egg cell membrane.

This case series was done to study endoscopic collagen spray as a hemostatic agent in peptic ulcer bleeding not controlled by conventional therapy.

\section{Materials and Methods}

This was a prospective study done on eighteen consecutive patients with peptic ulcer bleeding in a single centre. Inclusion criteria are as follows: 1 . Patients with hemorrhagic peptic ulcers, not controlled with conventional therapy 2 . Patients with hemorrhagic peptic ulcers not amenable to conventional therapy due to poor visibility. Conventional therapy was defined as use of intravenous proton pump inhibitor, and endotherapy with epinephrine injection, hemoclipping, and thermal coagulation. The hemorrhagic ulcers were treated with VGM's Haemoseal Spray Shaili, which delivers collagen in powder form. Patients with known allergy to egg (as collagen powder used in the study was prepared from egg cell membrane) or multiple allergies were excluded. The study was presented to the Institutional Ethical Committee and was approved. Informed consent was taken from all the patients. 
The endoscopic interventions were performed using Olympus Evis Exera III CV-180 \& 190 endoscopes (Olympus, Tokyo, Japan) by an experienced endoscopist. Haemoseal spray was used as a salvage technique after conventional therapy had failed. Failure of conventional therapy was defined as continuing ooze of blood or spurt of blood after endotherapy.

Haemoseal Spray Kit consists of an air pump, Haemoseal probe, a $7.5 \mathrm{Fr}$ spray catheter, $230 \mathrm{~cm}$ in length (Shaili Endoscopy, India) and a pre-loaded collagen cartridge containing five grams of powder (Figure 1). Spray catheter is passed through the working channel of the endoscope. Collagen powder is applied in short bursts through the spray catheter with air pump that drives in air which propels the preloaded collagen powder in the cartridge. The bellows provided in the cartridge can manually be used to pump the collagen powder without the use of the air pump. A burst on average contains 1 gram of powder and lasts about 10 seconds. A maximum of $2 \mathrm{~g}$ is applied depending on the area to be covered. The distal end of the catheter is placed 2 to $3 \mathrm{~cm}$ away from the hemorrhagic lesion in order to prevent sticking of the catheter in moisture.

Repeat endoscopy was done after 48 hours to check for hemostasis. The clinical data, details of the procedure, and occurrence of haemoglobin drop requiring blood transfusion were noted.

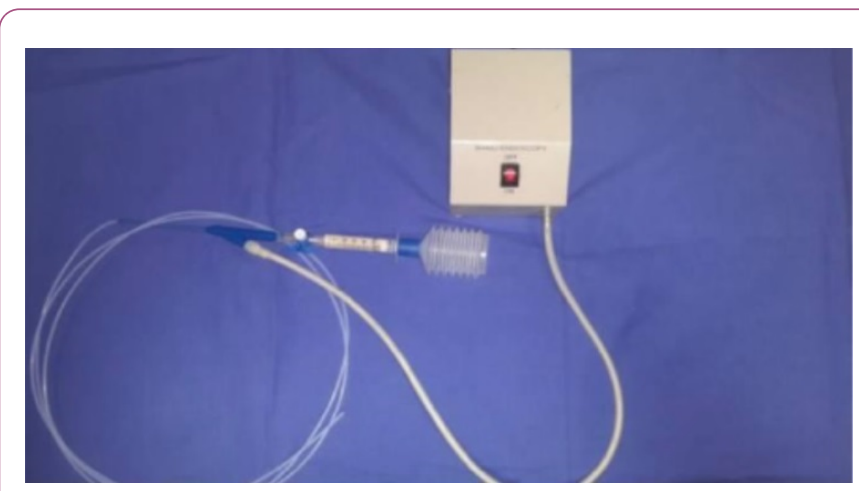

Figure 1 Haemoseal Spray Kit with air pump, Haemoseal probe, a $7.5 \mathrm{Fr}$ spray catheter, $230 \mathrm{~cm}$ in length (Shaili Endoscopy, India) and collagen cartridge.

\section{Results}

There were 18 patients in the study. The demographic and clinical data are as seen in the table (Table 1).

The patients who were on anti-platelets were taken off it. The patients were started on intravenous proton pump inhibitors. All the patients underwent endoscopy within 12 hours of admission. During endoscopy, diluted epinephrine was injected into the ulcer base. As the bleeding was not arrested, endoscopic collagen spray was done (Figures 2A-2C). The patient with haemophilia $B$ had duodenal ulcer with spurt of blood (Forrest la). The patient received Factor IX prior to the procedure. Epinephrine was injected around the ulcer base.
There was excessive bleeding and no vessel could be made out (Figure 3A). Collagen spray was done as a temporary measure (Figure 3B). The bleeding was controlled within seconds. Repeat endoscopy done 24 hours after the collagen spray showed a non- bleeding visible vessel (Figure $3 \mathbf{3}$ ). Hemoclipping was done (Figure 3D). There was no further bleeding on relook endoscopy. The other patient with Forrest la also had two sittings of endoscopy. During the first endoscopy, the bleeding was halted using collagen spray. During the second endoscopy, hemoclipping of visible vessel was done. Four patients were positive for Helicobacter pylori and were treated for it.

There was no drop-in hemoglobin or requirement of transfusion for any patient after the therapeutic intervention. All the patients had a relook endoscopy after 48 hours which demonstrated a clean based ulcer with no bleeding.

Table 1 Demographic and clinical data of the patients.

\begin{tabular}{|c|c|c|}
\hline $\begin{array}{l}\text { S } \\
\text { No. }\end{array}$ & Parameter & Data \\
\hline 1 & Age (in years) & 57.667 (Range 15-88) \\
\hline 2 & Gender (N) & Males-10, Females-8 \\
\hline 3 & $\begin{array}{l}\text { Use of antiplatelets/coagulopathy } \\
(\mathrm{N})\end{array}$ & Antiplatelets- 6 Hemophilia B-1 \\
\hline 4 & Site of bleed $(\mathrm{N})$ & $\begin{array}{ll}\text { Gastric-2 } & \text { Duodenal-16 } \\
\text { Jejunal-1 } & \end{array}$ \\
\hline 5 & Forrest classification $(\mathrm{N})$ & la-2 lb-16 \\
\hline 6 & $\begin{array}{l}\text { Helicobacter pylori by rapid } \\
\text { urease test }\end{array}$ & 4 \\
\hline 7 & Additional endotherapy & $\begin{array}{l}\text { Diluted epinephrine injection- } \\
18 \text { Hemoclipping-2 }\end{array}$ \\
\hline 8 & $\begin{array}{l}\text { Requirement of blood transfusion } \\
\text { after procedure }(\mathrm{N})\end{array}$ & 0 \\
\hline 9 & $\begin{array}{l}\text { Requirement of further therapeutic } \\
\text { intervention }(\mathrm{N})\end{array}$ & 2 \\
\hline
\end{tabular}

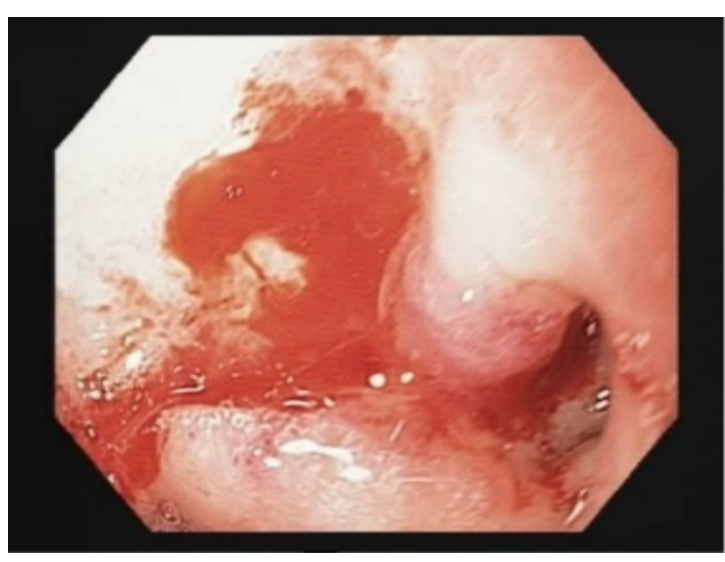

Figure 2A Duodenal ulcer with ooze. 


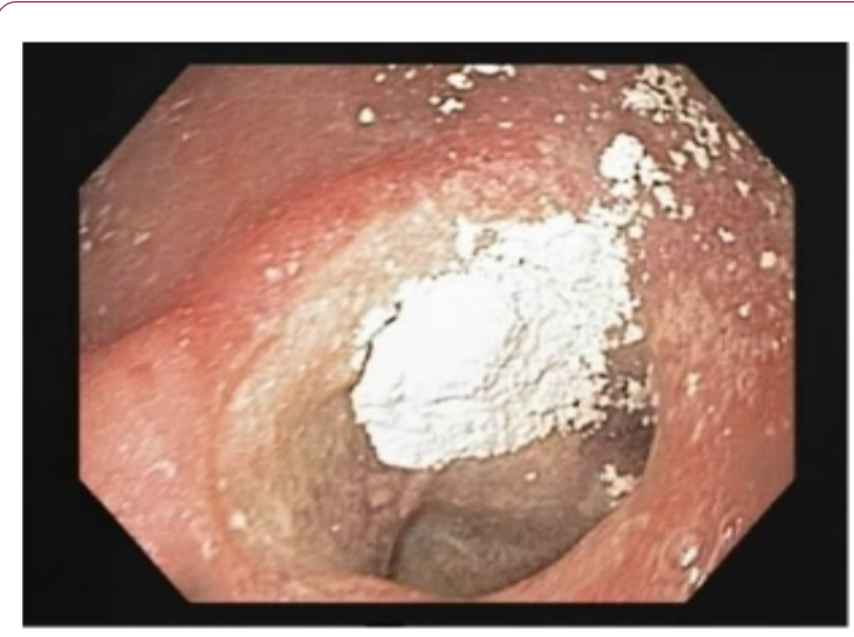

Figure 2B Collagen spray over the bleeding site.

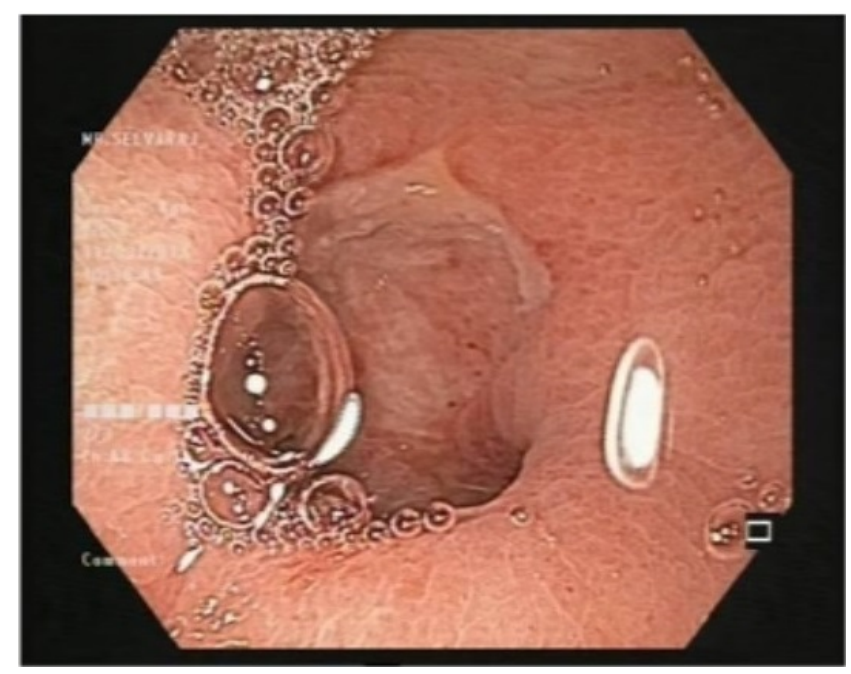

Figure 2C Relook endoscopy after 48 hours showing ulcer with clean base.

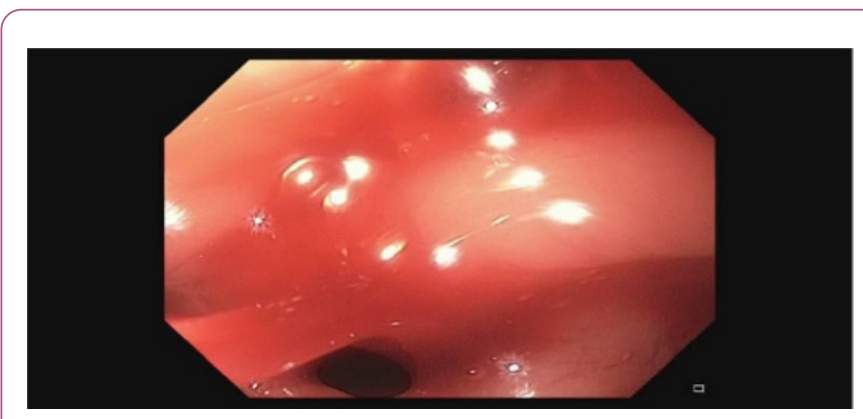

Figure 3A Arterial spurt from duodenal ulcer in a patient with Hemophilia B.

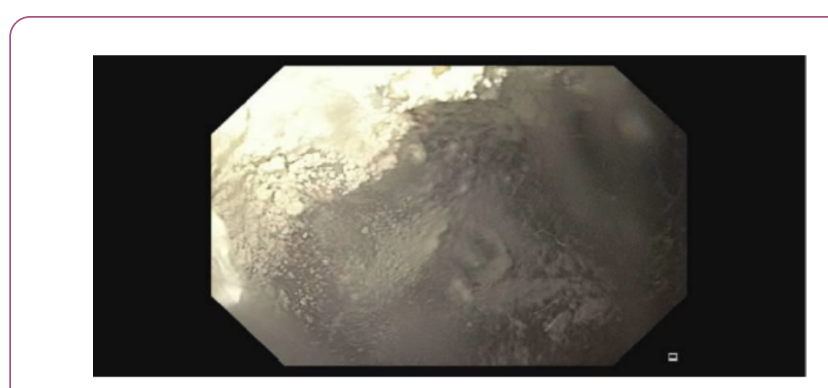

Figure 3B Collagen spray done over the bleeding site.

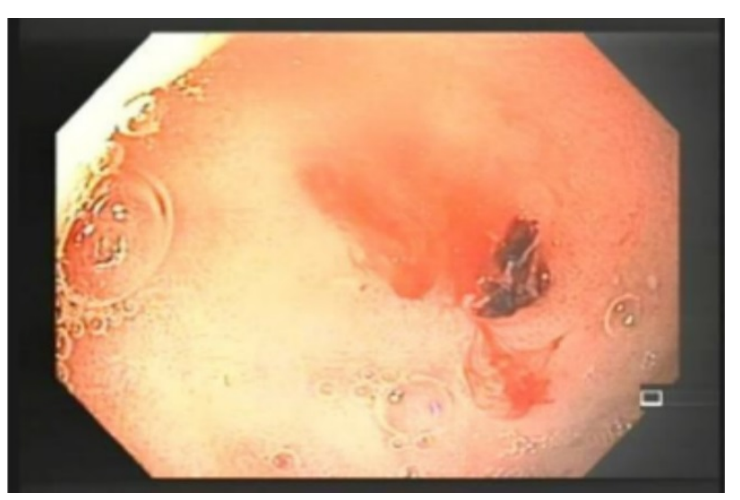

Figure 3C Visible vessel seen on endoscopy.

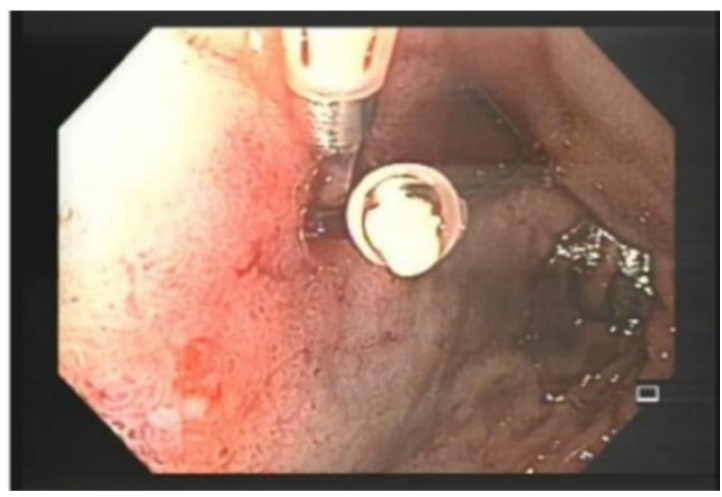

Figure 3D Hemoclipping of the visible vessel done.

\section{Discussion}

Collagen is the major protein of the extracellular matrix (ECM) and is the most abundant protein found in mammals. Collagen is of central importance in two aspects of hemostasis. Firstly, the intrinsic coagulation pathway is activated by collagen, which is exposed whenever a vessel is damaged. Secondly, it helps in platelet activation. Collagen acts as a structural scaffold in tissues because of the stiff, triplestranded helical structure $[4,5]$. Binding of platelets to collagen via the glycoprotein IV/IX/V receptor, induces a trans-bilayer flip of lipids in platelet membrane, thus exposing procoagulant phospholipids, leading to thrombosis. Von Willebrand factor, integrins and clotting factors also bind collagen $[6,7]$. 
Collagen based products have been used in surgical hemostasis since 1970 in the US. The first collagen based microfibrillar hemostatic, Avitene, is even now widely used in the topical powder form. Among surgical hemostatic agents, collagen based products were found to be more effective than gelatin- based products. [8] In a comparative study in high transfusion risk cardiac surgery, collagen was found to be superior to oxidised cellulose with respect to significant bloodloss reduction [9].

Although hemostatic powders have been in use in various surgeries, their use in endoscopy is of recent interest. Ankaferd Blood Stopper (ABS), Hemospray TC- 325, Endoclot polysaccharide hemostatic system are the agents which are currently in use $[3,10,11]$. They act by forming a mechanical tamponade. They also act by concentrating cells and protein, thereby activating certain steps of coagulation cascade. On the other hand, collagen is directly involved in several important steps of the coagulation process and hence is the most physiological hemostatic agent. If the primary risk of hemorrhage for a particular lesion stems from immediate bleeding without a significant risk of delayed rebleeding, hemostatic powder may suffice as a single modality treatment [3]. Collagen is more physiological in comparison to the other available hemostatic sprays. Moreover, it has been used in surgery for forty years, without any untoward side effects. Being an integral part of the human tissue, it poses no toxic insult to the tissue. Theoretically, allergic reactions to the parent animal tissue protein is still a possibility.

Collagen has a physiologic role in healing of all wounds in the human body. Spraying collagen not only initiates the clotting cascade, but also hastens the reparative processes. It has been shown in a study that collagen administered topically could initiate wound healing through activation of inflammatory cells and vascularisation of the tissue [12]. Collagen can induce fibroblastic growth which is necessary for formation of granulation tissue. Collagen cleavage products stimulate angiogenic growth factors and epithelial cell migration and proliferation. These processes help in achieving re-epithelialisation $[13,14]$. Resorbable forms of collagen have been used to dress oral wounds, for closure of graft and in implant therapy [15]. Thus, in addition, the role of collagen in tissue healing makes it more physiologic, establishing an edge over spraying inert-particles which can give only a tamponade.

The collagen spray is simple to use. It requires no skill requiring manoeuvres. It can be used in locations hard to access, for example, the posterior wall of duodenum, where there is difficulty in bringing out and positioning accessories. It can be used as a temporary measure to halt the bleeding, when other techniques cannot be effectively used. For example, in the current study, the patients with ulcer and spurting vessel, hemoclipping could not be done due to poor visiblity. However, collagen spraying as a rescue therapy, bought time for a relook endoscopy after 24 hours. At that time, the bleeding had stopped and hemoclipping of the nonbleeding visible vessel could be done.

In this case series, there were no adverse effects experienced by the patients. There was temporary discomfort reported with other hemostatic sprays, due to rapid air insufflation and gastric distension. There is an occasional clogging of the pump, by inadvertent contact of collagen with water, which is easily managed with passing of air by the motorised air pump. Precaution is taken to prevent tip of catheter from coming in contact with body fluids.

\section{Conclusion}

Endoscopic collagen spray is simple to use. It can be performed by trainees as well. In this case series, no adverse effects of the therapy were observed. All the patients recovered from the peptic ulcer bleeding. Often times when a bleeding lesion is countered on endoscopy, visualization is impaired because of the bleeding (as was the case with one patient in this series). It is difficult to use conventional endoscopic techniques in a poorly visualized field. Another instance where it is difficult to use conventional therapy, is the junction between the first and second part of the duodenum. In both these situations, collagen spray is advocated by the author, as the catheter can be easily positioned and sprayed. Once the bleeding is controlled, the visible vessel or lesion could be identified, and conventional therapy can be used. Collagen spray can be used as an endoscopic hemostatic agent in peptic ulcer bleeding, as an adjunct to conventional therapy. Further comparative studies are needed to establish its place in the armamentarium of hemostatic agents.

\section{References}

1. Gralnek IM, Jensen DM, Gornbein J, Kovacs TO, Jutabha R, et al. (1998) Clinical and economic outcomes of individuals with severe peptic ulcer hemorrhage and non-bleeding visible vessel: An analysis of two prospective clinical trials. Am J Gastroenterol 93: 2047-2056.

2. Laine L, Jensen DM (2012) Management of patients with ulcer bleeding. Am J Gastroenterol 107:345-360.

3. Barkun AN, Moosavi S, Martel M (2013) Topical hemostatic agents: A systematic review with particular emphasis on endoscopic application in GI bleeding. Gastrointest Endosc 77: 692-700.

4. Boucher BA, Traub O (2009) Achieving hemostasis in the surgical field. Pharmacother 29: 2S-7S.

5. Hess JR, Brohi K, Dutton RP, Hauser CJ, Holcomb JB, et al. (2008) The coagulopathy of trauma: A review of mechanisms. J Trauma 65: 748-754.

6. Rubin E, Gorstein F, Rubin R, Schwarting R, Strayer D (2005) Rubin's pathology: Clinicopathologic foundations of medicine. Lippincott Williams and Wilkins, Baltimore, US ${ }^{\mathrm{A}}$.

7. Franchini M, Lippi G (2010) Factor V Leiden and hemophilia. Thromb Res. 125: 119-123.

8. Sundaram CP, Keenan AC (2010) Evolution of hemostatic agents in surgical practice. Indian J Urol 26: 374-378.

9. Sirlak M, Eryilmaz S, Yazicioglu L, Kiziltepe $U$, Eyileten $Z$, et al. (2003) Comparative study of microfibrillar collagen hemostat (Colgel) and oxidized cellulose (Surgicel) in high transfusion-risk cardiac surgery. J Thorac Cardiovasc Surg 126: 666-670. 
10. Sung JJ, Luo D, Wu JC, Ching JY, Chan FK, et al. (2011) Early clinical experience of the safety and effectiveness of Hemospray in achieving hemostasis in patients with acute peptic ulcer bleeding. Endoscopy 43: 291-295.

11. Barkun A (2013) New topical hemostatic powders in endoscopy. Gastroenterol Hepatol 9: 744-746.

12. Montesano R, Orci L, Vasselli $P$ (1983) In vitro rapid organization of endothelial cells into capillary-like networks is promoted by collagen matrices. J Cell Biol 97: 1648-1652.
13. Madri JA, Marx M (1992) Matrix composition, organization, and soluble factors: modulators of microvascular cell differentiation in vitro. Kidney Int 41: 560-565.

14. Albini A, Adelmann-Grill BC (1985) Collagenolytic cleavage products of collagen Type I as chemoattractants for human dermal fibroblasts. Eur J Cell Biol 36: 104-107.

15. Khan R, Khan MH (2013) Use of collagen as a biomaterial: An update. J Indian Soc Periodontol 17: 539-542. 